\title{
Long-Term Fracture Resistance of Simulated Immature Teeth Filled with Various Calcium Silicate-Based Materials
}

\author{
Yeliz Guven, ${ }^{1}$ Elif Bahar Tuna, ${ }^{1}$ M. Emir Dincol, ${ }^{2}$ Emre Ozel, ${ }^{3}$ \\ Bulent Yilmaz, ${ }^{2}$ and Oya Aktoren ${ }^{1}$ \\ ${ }^{1}$ Department of Pedodontics, Faculty of Dentistry, Istanbul University, 34093 Istanbul, Turkey \\ ${ }^{2}$ Department of Endodontics, Faculty of Dentistry, Istanbul University, 34093 Istanbul, Turkey \\ ${ }^{3}$ Department of Restorative Dentistry, Faculty of Dentistry, University of Kocaeli, 41190 Kocaeli, Turkey
}

Correspondence should be addressed to Yeliz Guven; yelizgn@gmail.com

Received 14 February 2016; Revised 16 April 2016; Accepted 18 May 2016

Academic Editor: Nick Silikas

Copyright (C) 2016 Yeliz Guven et al. This is an open access article distributed under the Creative Commons Attribution License, which permits unrestricted use, distribution, and reproduction in any medium, provided the original work is properly cited.

Objective. The aim of this in vitro study was to evaluate the long-term fracture resistance of simulated human immature permanent teeth filled with BioAggregate ${ }^{\text {Tw }}$ (BA), mineral trioxide aggregate (MTA), and EndoSequence ${ }^{\oplus}$ Root Repair Material (ERRM). Material and Methods. 40 teeth, simulated to average root length of $13 \pm 1 \mathrm{~mm}$ (Cvek's stage 3), were included in the study. The teeth were randomly divided into four groups: Group 1: DiaRoot ${ }^{\circledR}$ BA, Group 2: MTA-Plus ${ }^{\mathrm{Tm}}$ (MTA-P), Group 3: MTA-Angelus (MTA-A), and Group 4: ERRM. The root canal filling materials were applied according to the manufacturers' instructions. After 24 months of incubation, the roots of the teeth were embedded in acrylic blocks and subjected to fracture testing. The resultant data were analyzed statistically by Kruskal-Wallis and Mann-Whitney $U$ tests. Results. Mean ( \pm SD) failure loads (MPa) were $20.46 \pm 2.53$ for BA, $18.88 \pm 5.13$ for MTA-P, $14.12 \pm 1.99$ for MTA-A, and 17.65 \pm 4.28 for ERRM groups. BA group exhibited the highest and MTA-A group showed the lowest resistance to fracture. Significant differences in fracture resistance were found between the groups of BA and MTA-A $(p<0.001)$, MTA-P and MTA-A $(p<0.05)$, and ERRM and MTA-A $(p<0.05)$. Conclusion. Within the limitations of this study, data suggests that BA-filled immature teeth demonstrate higher fracture resistance than other groups at 24 months appearing to be the most promising material tested.

\section{Introduction}

Traumatic dental injuries are frequent in children aged 812 years, and the maxillary incisors are the most commonly affected teeth. A traumatic impact on the immature anterior teeth frequently results in arrested root development due to the loss of pulp vitality. The endodontic treatment of these teeth with necrotic pulps poses a challenge for the practitioner because of the widely open apices and the thin dentinal walls which predispose teeth to fracturing $[1,2]$. Root fractures commonly occur in the cervical third and have been shown to have a rate of about $28-77 \%$, depending on the stage of root development, with the highest percentage of fractures occurring in teeth with the least developed roots [3].

An optimal approach to treating the immature permanent tooth with a necrotic pulp would be to regenerate functional pulpal tissue and subsequently promote continued root development and apical closure [4]. A regenerative endodontic procedure, revascularization, was presented recently to treat immature permanent teeth. Although it has demonstrated great potential for clinical success, it needs to be evaluated over the long term, and it may not be successful in every case [5]. Accordingly, apexification through the use of calcium hydroxide $(\mathrm{CH})$ or mineral trioxide aggregate (MTA) still represents the most widely indicated treatment for necrotic cases of immature teeth. $\mathrm{CH}$ apexification by means of the induction of an apical barrier and the antibacterial capacity of the agent-due to its high $\mathrm{pH}$ - has been used for more than 50 years and has proved to be successful in apical healing [6]. However, long-term application of $\mathrm{CH}$ has been reported to possess numerous disadvantages, including long duration of treatment and requirement for multiple appointments. The risk of fractures between appointments and the possibility of recontamination due to the dislodgement of 
temporary filling are additional shortcomings of $\mathrm{CH}$ apexification. Single visit apexification using MTA has recently been advocated to overcome these difficulties inherent in long-term $\mathrm{CH}$ treatment, and it has resulted in favorable clinical outcomes $[7,8]$. Immediate apical barrier formation using MTA offers several advantages over conventional apexification, such as reduced risk of subsequent cervical root fracture and increased patient compliance. Aside from these advantages, however, MTA is difficult to handle and has a long setting time, and its high cost restricts its clinical application $[7,9]$.

The search for bioceramic materials exhibiting properties similar to MTA but with improved handling characteristics and shorter setting times has led to the development of newer products which have been referred to as calcium silicatebased cements. BioAggregate (BA) (Innovative BioCeramix Inc., Vancouver, BC, Canada), a tricalcium silicate-based and aluminum-free ceramic biomaterial, has been developed for use in retrograde root filling, repair of root perforation, apexification, vital pulp therapy, and pulp capping $[9,10]$. EndoSequence Root Repair Material (ERRM) has recently been introduced to the dental market. The material uses bioceramic technology and is produced in a premixed state, either with a ready-to-use syringeable paste or compactable putty, both of which provide easier handling and application than MTA. ERRM is composed of zirconium oxide, calcium silicates, tantalum oxide, calcium phosphate monobasic, and filler agents [11]. Although all calcium silicate-based materials induce clinically perceptible color changes, BA and ERRM are also advantageous since they exhibit less discoloration than MTA $[12,13]$.

Calcium silicate-based materials have been proposed as a promising alternative to $\mathrm{CH}$ in apexification procedures because of their high biocompatibility and their superior ability to set in the presence of moisture. Despite favorable clinical and laboratory outcomes obtained when using these calcium silicate-based materials to treat teeth with immature apexes, the high rate of cervical root fractures in the long term is still a significant concern. Accordingly, ongoing efforts have been directed towards searching for materials with improved biological and mechanical properties. Furthermore, there has been limited information on the strengthening capacity of novel root canal filling materials. In this regard, the aim of this in vitro study was to assess the long-term fracture strength of simulated human immature permanent teeth filled with BA, MTA, and ERRM.

\section{Materials and Methods}

2.1. Tooth Selection. Extracted human maxillary central incisor teeth, thoroughly hand-scaled and cleaned with water/pumice slurry using a low-speed handpiece, were stored in distilled water at $4^{\circ} \mathrm{C}$ until use. All teeth were examined under $\times 4$ magnification, and only intact teeth without cracks, fractures, or caries were included in the study. Preoperative radiographs were taken in the faciolingual and mesiodistal directions to confirm the presence of a single canal without resorptions or calcifications. The selected teeth were measured with a digital caliper in the buccolingual and

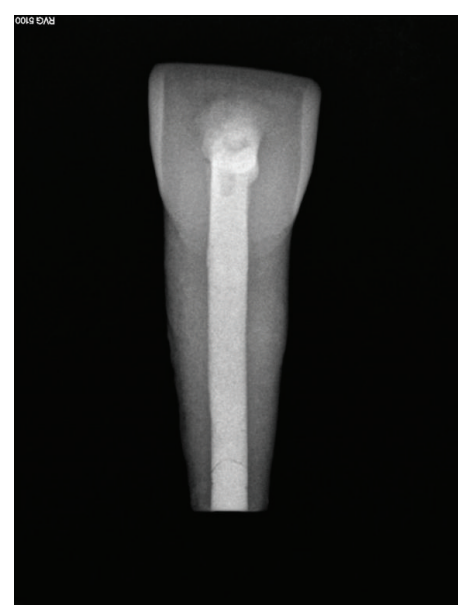

FIGURE 1: Frontal view of the simulated immature teeth after root filling.

mesiodistal dimensions at the cementoenamel junction (CEJ) and the mean values were obtained. Teeth displaying more than $10 \%$ deviation were excluded, leaving 40 teeth for use in the study. All procedures were performed by the same experienced operator.

The root of each tooth was standardized to a length of $13 \pm$ $1 \mathrm{~mm}$ as measured from the apex to the facial CEJ by cutting off the root end to simulate immature teeth (Cvek's stage 3). The length of the specimens was measured by digital caliper.

2.2. Treatment Procedures. Coronal access was made using a \#10 round diamond bur (Strauss \& Co., Industrial Diamonds Ltd. Rảanana, Israel) and endo-Z bur (Dentsply Maillefer, Ballaigues, Switzerland) in a high speed handpiece. The pulps were extirpated using barbed broaches (DiaDent Group Int., Canada). To simulate immature teeth, the root canals were instrumented with Peeso reamers (Dentsply Maillefer, Ballaigues, Switzerland) between \#1 and \#6 until a size 6 Peeso $(1.7 \mathrm{~mm})$ could be passed $1 \mathrm{~mm}$ beyond the apex. The canals were irrigated with $5 \mathrm{~mL} 5.25 \%$ sodium hypochlorite ( $\mathrm{NaOCl}$ (Sultan Chemists Inc., Englewood, USA), $5 \mathrm{~mL}$ 17\% EDTA (Pulpdent Corporation, Watertown, MA, USA), and $5 \mathrm{~mL}$. $0.9 \%$ saline, respectively. During all of the procedures, teeth were wrapped in moistened gauze. After instrumentation and irrigation, the canals of the teeth were filled with the root canal filling materials according to manufacturers' instructions.

Manufacturers and composition of the materials used in the study are summarized in Table 1 . Figure 1 shows the radiographic appearance of a representative sample of an immature tooth obturated with respective root canal filling material.

The teeth were randomly assigned to four groups of ten teeth each, given as follows.

Group 1 (DiaRoot BA (BA) (DiaDent Group International, Canada)). $1 \mathrm{~g}$ of BA powder was mixed with $0.38 \mathrm{~mL}$ of liquid included in the package according to the manufacturer's instructions. Teeth were filled using lentulo spiral (Mani Inc., 
TABLE 1: Manufacturer names and composition of the root canal filling materials used in the study.

\begin{tabular}{lll}
\hline Material & Company & Major chemical compounds \\
\hline BioAggregate & $\begin{array}{l}\text { DiaDent Group International, } \\
\text { Canada }\end{array}$ & $\begin{array}{l}\text { Tricalcium silicate, dicalcium silicate, tantalum pentoxide, calcium } \\
\text { phosphate monobasic, amorphous silicon oxide }\end{array}$ \\
\hline MTA-Angelus & Angelus, Londrina, PR, Brazil & $\begin{array}{l}\text { Tricalcium silicate, dicalcium silicate, tricalcium aluminate, } \\
\text { tetracalcium aluminoferrite, bismuth oxide }\end{array}$ \\
\hline $\begin{array}{l}\text { EndoSequence Root Repair } \\
\text { Material }\end{array}$ & $\begin{array}{l}\text { Avalon Biomed Inc. by Prevest } \\
\text { Denpro Limited, India }\end{array}$ & $\begin{array}{l}\text { Tricalcium silicate, dicalcium silicate, bismuth oxide, calcium } \\
\text { sulfate, silica }\end{array}$ \\
\hline
\end{tabular}

Tochigi-Ken, Japan) and pluggers. The apices and the coronal parts were covered with a moist cotton pellet for 12 hours before placing the permanent restoration.

Group 2 (MTA-Plus (MTA-P) (Avalon Biomed Inc., Prevest Denpro Limited, India)). The root canal was filled with MTA$\mathrm{P}$ which is provided with either water or a gel for mixing. In the present study, it was mixed with water. The paste was carried to the coronal part of the pulp cavity using a lentulo spiral, and it was condensed using pluggers. The manufacturer indicates no specific requirement for moisture to allow finalization of the setting reaction.

Group 3 (MTA-Angelus (MTA-A) (Angelus Soluções Odontológicas, Londrina, PR, Brazil)). The white MTA-A was placed in the root canal using a lentulo spiral and then condensed using pluggers. The moisture is not required for setting reaction.

Group 4 (EndoSequence Root Repair Material (ERRM) (Brasseler, USA)). ERRM was introduced into the entire root canal using the manufacturer-provided preloaded syringe with the delivery tip. The manufacturer does not indicate any moisture-specific instructions to allow finalization of the setting reaction.

All specimens were radiographed from lateral and facial views of the teeth after the root treatment to verify the filling density. In all groups, after the radiographic confirmation, the coronal access of each specimen was restored with a glass ionomer base (Fuji II LC; GC America, Inc.) and composite resin filling (Filtek Z250, 3M ESPE, St. Paul, MN, USA). The coronal access of all teeth was restored with glass ionomers (Fuji II LC; GC America Inc.), followed by composite resins (Filtek Z250, 3M ESPE, St. Paul, MN, USA). All specimens were stored in $100 \%$ humidity at $37^{\circ} \mathrm{C}$ for 24 months until fracture resistance testing.

2.3. Fracture Strength Test. The root of each tooth was embedded vertically in self-curing orthodontic resin blocks (Dentsply, Tulsa, OK) with dimensions of $27 \mathrm{~mm} \times 15 \mathrm{~mm} \times$ $13 \mathrm{~mm}$. The long axis of each tooth was aligned with the central axis of the acrylic resin block. The roots were submerged in acrylic resin, leaving a $2 \mathrm{~mm}$ gap between the CEJ and the top of the resin to simulate the relation between the tooth

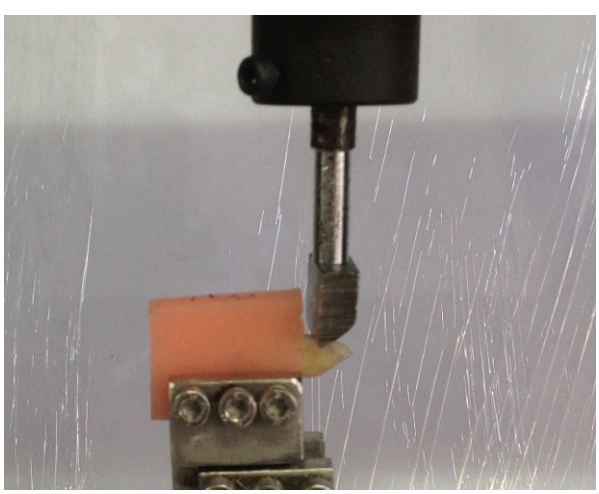

FIGURE 2: Compression force was applied at a point $3 \mathrm{~mm}$ from the CEJ and perpendicular to the long axis of the tooth with an Instron Universal Testing Machine.

and the bone crest. The spade was placed on the facial surface at a point $3 \mathrm{~mm}$ above the CEJ, and loading was applied perpendicular to the specimen's long axis at a cross head speed of $1 \mathrm{~mm} / \mathrm{min}$ in a universal testing machine (Instron, AG-IS, Shimadzu, Japan) until the initial fracture occurred (Figure 2). The maximum load at which the samples fractured was recorded in Newtons (N), and the fracture strength (force/area) was calculated in MPa.

2.4. Statistical Analysis. The mean and standard deviation (SD) for each group was calculated. The findings were analyzed statistically using a Kruskal-Wallis test to detect any intergroup differences and by means of the Mann-Whitney $U$ test to evaluate comparisons at a $5 \%$ level of significance.

\section{Results}

The mean fracture strength values and SD for all groups are shown in Table 2. Mean $( \pm \mathrm{SD})$ failure loads $(\mathrm{MPa})$ were $20.46 \pm 2.53$ for BA, $18.88 \pm 5.13$ for MTA-P, $14.12 \pm 1.99$ for MTA-A, and $17.65 \pm 4.28$ for ERRM groups. All specimens showed either oblique or horizontal fractures through the cervical area of the root.

Significant differences were found in failure loads among all tested groups according to the results of the Kruskal-Wallis analysis of variance $(p<0.01)$. The BA group exhibited the highest and the MTA-A group showed the lowest resistance 
TABLE 2: Mean fracture strengths ( $\mathrm{MPa})$ of teeth treated with BA, MTA-A, MTA-P, and ERRM at 24-month period and intergroup comparison of difference in fracture strength.

\begin{tabular}{|c|c|c|c|}
\hline \multirow{2}{*}{ Groups } & \multicolumn{2}{|c|}{ Fracture strength } & \multirow{2}{*}{${ }^{+} p$} \\
\hline & Mean \pm SD & Median & \\
\hline${ }^{1} \mathrm{BA}$ & $20.46 \pm 2.53$ & $21.04(15.78-23.31)$ & \multirow{4}{*}{$0.005^{* *}$} \\
\hline${ }^{2}$ MTA-P & $18.88 \pm 5.13$ & $17.45(11.25-25.37)$ & \\
\hline${ }^{3}$ MTA-A & $14.12 \pm 1.99$ & $13.61(11.71-18.02)$ & \\
\hline${ }^{4}$ ERRM & $17.65 \pm 4.28$ & $16.66(12.57-26.37)$ & \\
\hline $1-2^{\dagger} p$ & & 0.739 & \\
\hline $1-3^{\dagger} p$ & & $0.001^{* *}$ & \\
\hline $1-4^{\dagger} p$ & & 0.063 & \\
\hline $2-3^{\dagger} p$ & & $0.029^{*}$ & \\
\hline $2-4^{\dagger} p$ & & 0.579 & \\
\hline $3-4^{\dagger} p$ & & $0.035^{*}$ & \\
\hline
\end{tabular}

${ }^{+}$Kruskal-Wallis test; ${ }^{\dagger}$ Mann-Whitney $U$ test; ${ }^{* *} p<0.01 ;{ }^{*} p<0.05$.

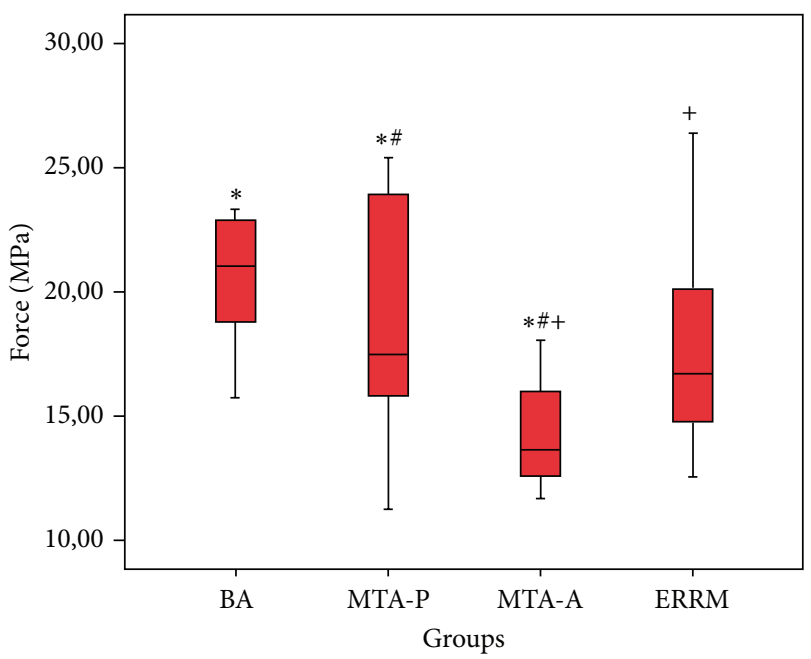

Figure 3: Boxplots with forces required to cause cervical root fracture for each of the groups. *, \#, and + symbols represent significant differences $(p<0.05)$.

to fracture. Significant differences in fracture resistance were found between the BA and MTA-A and MTA-Plus and MTAAngelus and also between ERRM and MTA-A groups $(p<$ 0.05) (Figure 3). The Mann-Whitney $U$ test revealed no other significant differences $(p>0.05)$ between the other groups (Table 2).

\section{Discussion}

Endodontically treated immature teeth are susceptible to fracture depending on their stage of root development, which is directly related to the remaining dentin wall thickness and root length [3]. It is well established that as the dentin wall thickness decreases, the resistance to fracture decreases as well, and therefore it becomes more important to select a material that has potential to reinforce the root structure $[5,14]$. A number of studies have focused on increasing fracture resistance of immature teeth using various techniques [15-19]. MTA has been a revolutionary material in endodontics because of its high biocompatibility and sealing ability. Due to the promising results obtained with MTA, a new generation of endodontic materials with similar composition to MTA, but with some modifications aimed at overcoming the current drawbacks of the original material, has been developed and named calcium silicatebased cements because of their primary components of calcium and silicate $[20,21]$. This in vitro study was conducted to investigate the long-term fracture strength of simulated human immature permanent teeth filled with three different calcium silicate-based materials: MTA, BA, and ERRM.

The methods for the simulation of immature teeth and preparation of the models for the fracture strength tests differed widely among previous studies [22]. In those studies, the analysis of the fracture resistance has been tested using sheep $[1,23]$ or bovine teeth $[18,24]$ or simulated human teeth $[5,19,25,26]$ or immature teeth extracted for orthodontic purposes [16]. This study used a simulated immature tooth model similar to that of Hemalatha et al. [26].

The mature teeth used in the present study may simulate the morphology of immature teeth, but they may not simulate the tissue composition and physical characteristics exactly, and this may be considered a limitation of these kinds of studies as stated by Ulusoy et al. [22]. Nevertheless, all of the experimental teeth went through the same procedures for the simulation of immature teeth; therefore, it can be assumed that they still allow for a relative comparison for assessing the resistance of immature teeth to fracture [17]. Only maxillary central incisors were used in the present study, as they are more susceptible to trauma and external impacts owing to their localizations.

Previous studies have evaluated the fracture resistance of immature teeth restored by various root canal filling systems, such as composite resin, fiber post, gutta-percha $[1,27]$, MTA [16], and recently introduced calcium silicate-based materials including Biodentine [19] and BA [16].

The nanosphere structure of ERRM particles allows the material to penetrate into the dentinal tubules and interact with the moisture inside the tubules for final setting. This creates a mechanical bond with dentine upon setting and renders the material with exceptional dimensional stability [28, 29]. The material has additional properties such as a high alkaline $\mathrm{pH}$, radiopacity, hydrophilic setting properties, and ideal working (more than $30 \mathrm{~min}$ ) and setting time [28]. These properties of ERRM have led to consideration of its usage for repair of root perforations, root-end fillings, pulp capping, pulpotomy, and root canal obturation [20]. Currently, there is very limited research on ERRM regarding its usage on root canal obturation. It has mainly been evaluated for use as a root-end filling material. Furthermore, there is no data regarding the fracture resistance of teeth filled with ERRM. In the present study, ERRM has been investigated for the first time with regard to its fracture resistance and has been found to have a significantly higher fracture resistance than MTA-A after 2 years. No significant difference was observed when compared to BA and MTA-P.

BA is composed of fine nanoparticle-size, aluminumfree powder that is mixed with deionized water to form 
a bioceramic paste [20]. BA contains hydroxyapatite, which has been proposed as an addition to root-end filling materials in order to enhance their ability to form a biochemical bond to the bone [30].

Tuna et al. assessed the long-term fracture resistance of human immature permanent teeth filled with BA, MTA, and $\mathrm{CH}$ and reported that the immature teeth filled with $\mathrm{BA}$ showed the highest fracture resistance in all groups, although statistically significant difference was observed only between $\mathrm{BA}$ and $\mathrm{CH}$ groups [16]. The results of the present investigation correlate well with those reported by Tuna et al. [16]. In the current study, the BA group showed higher resistance to fracture than other groups, although this difference only reached statistical significance on comparison with MTA-A group. The high fracture resistance of BA may be attributed to the absence of calcium hydroxide in the aged cement considering the negative long-term effects of calcium hydroxide on the fracture susceptibility of the root. Camilleri et al. investigated the effects of additives on the hydration mechanism of BA by characterization of the unhydrated and hydrated forms, using a combination of techniques and comparing these properties to MTA-Angelus [31]. Tricalcium silicate in BA results in calcium silicate hydrate and calcium hydroxide following setting reactions. The former was deposited around the cement grains, while the latter reacted with the additive in $\mathrm{BA}$, silicon dioxide, to form additional calcium silicate hydrate. This resulted in very low levels of calcium hydroxide in the aged cement thus enhancing the mechanical properties of the cement. MTA-A reacted in a similar fashion; however, since it contained no additives, the calcium hydroxide was still present in the aged cement [31].

Variations on the formulation have been made to overcome the drawbacks associated with MTA. MTA-A and MTA-P are two of those products. MTA-A exhibits a reduced setting time as a result of a lower concentration of calcium sulfate, and with a lower radiopacity due to the lower content of bismuth oxide in its composition $[21,32]$. MTA-P, which is claimed to have a finer particle size than currently available MTA brands, has been provided with either water or a hydrosoluble gel to improve its washout resistance (Avalon Biomed). A number of previous studies evaluated the fracture resistance of teeth completely filled with MTA, and conflicting findings were obtained. Fracture resistance of the teeth filled with MTA was found to be higher than those filled with $\mathrm{CH}[23,33]$ or those filled with gutta-percha [2]. On the contrary, there have been some studies reporting that MTA did not have a significant effect on root strengthening $[18,24]$. Tuna et al. tested the fracture resistance in human immature premolars using two different brands of MTA (MTA-A and MTA-PR), BA and CH [16]. Although MTA-A demonstrated significantly higher fracture resistance than MTA-PR, the difference did not reach statistical significance. In the present study, recent MTA brands MTA-P and MTA-A were tested, and MTA-P exhibited significantly higher fracture resistance than MTA-A. This result might be explained by the results of a recent investigation which has indicated that MTA-Plus (with either water or hydrosoluble gel) has a significantly lower washout compared to MTA-A [34].
In conclusion, the results of this in vitro study suggest that BA-filled immature teeth have higher fracture resistance than other groups at 24 months. In addition, the teeth filled with MTA-A demonstrated significantly lower strength to fracture in comparison with other groups. Considering the risk of cervical root fracture in the long term, it seems that BA could be a promising material. Further research is necessary to validate the findings obtained in the present study.

\section{Competing Interests}

The authors have no competing interests in any way with the products, materials, or suppliers used in this paper.

\section{Acknowledgments}

This work was supported by Scientific Research Projects Coordination Unit of Istanbul University, Project no. 201621064.

\section{References}

[1] K. L. Wilkinson, T. J. Beeson, and T. C. Kirkpatrick, "Fracture resistance of simulated immature teeth filled with resilon, guttapercha, or composite," Journal of Endodontics, vol. 33, no. 4, pp. 480-483, 2007.

[2] R. G. E. Cauwels, I. Y. Pieters, L. C. Martens, and R. M. H. Verbeeck, "Fracture resistance and reinforcement of immature roots with gutta percha, mineral trioxide aggregate and calcium phosphate bone cement: a standardized in vitro model," Dental Traumatology, vol. 26, no. 2, pp. 137-142, 2010.

[3] M. Cvek, "Prognosis of luxated non-vital maxillary incisors treated with calcium hydroxide and filled with gutta-percha. A retrospective clinical study," Endodontics \& Dental Traumatology, vol. 8, no. 2, pp. 45-55, 1992.

[4] K. M. Hargreaves, A. Diogenes, and F. B. Teixeira, “Treatment options: biological basis of regenerative endodontic procedures," Journal of Endodontics, vol. 39, no. 3, pp. S30-S43, 2013.

[5] H. S. Topçuoğlu, B. Kesim, S. Düzgün, Ö. Tuncay, S. Demirbuga, and G. Topçuoğlu, "The effect of various backfilling techniques on the fracture resistance of simulated immature teeth performed apical plug with Biodentine," International Journal of Paediatric Dentistry, vol. 25, no. 4, pp. 248-254, 2015.

[6] Z. Mohammadi and P. M. H. Dummer, "Properties and applications of calcium hydroxide in endodontics and dental traumatology," International Endodontic Journal, vol. 44, no. 8, pp. 697-730, 2011.

[7] I. Dikbas, J. Tanalp, T. Koksal, A. Yalniz, and T. Güngör, "Investigation of the effect of different prefabricated intracanal posts on fracture resistance of simulated immature teeth," Dental Traumatology, vol. 30, no. 1, pp. 49-54, 2014.

[8] M. Trope, "Treatment of the immature tooth with a non-vital pulp and apical periodontitis," Dental Clinics of North America, vol. 54, no. 2, pp. 313-324, 2010.

[9] A. E. Dawood, P. Parashos, R. H. Wong, E. C. Reynolds, and D. J. Manton, "Calcium silicate-based cements: composition, properties, and clinical applications," Journal of Investigative and Clinical Dentistry, 2015.

[10] J.-W. Park, S.-H. Hong, J.-H. Kim, S.-J. Lee, and S.-J. Shin, “XRay diffraction analysis of white ProRoot MTA and Diadent BioAggregate," Oral Surgery, Oral Medicine, Oral Pathology, 
Oral Radiology and Endodontology, vol. 109, no. 1, pp. 155-158, 2010.

[11] Brasselerusa product page. Brasseler USA ${ }^{\oplus}$ Endodontic Product Guide. Brasseler USA ${ }^{\oplus}$, http://brasselerusadental.com/catalogs/ endodontic-guide/.

[12] C. Keskin, E. O. Demiryurek, and T. Ozyurek, "Color stabilities of calcium silicate-based materials in contact with different irrigation solutions," Journal of Endodontics, vol. 41, no. 3, pp. 409-411, 2015.

[13] L. J. Marconyak Jr., T. C. Kirkpatrick, H. W. Roberts et al., "A comparison of coronal tooth discoloration elicited by various endodontic reparative materials," Journal of Endodontics, vol. 42, no. 3, pp. 470-473, 2016.

[14] C. H. Stuart, S. A. Schwartz, and T. J. Beeson, "Reinforcement of immature roots with a new resin filling material," Journal of Endodontics, vol. 32, no. 4, pp. 350-353, 2006.

[15] G. Sivieri-Araujo, M. Tanomaru-Filho, J. M. G. Tanomaru, E. A. Bortoluzzi, É. G. Jorge, and J. M. D. S. N. Reis, "Fracture resistance of simulatedimmature teeth after different intraradicular treatments," Brazilian Dental Journal, vol. 26, no. 3, pp. 211-215, 2015.

[16] E. B. Tuna, M. E. Dinçol, K. Gençay, and O. Aktören, "Fracture resistance of immature teeth filled with BioAggregate, mineral trioxide aggregate and calcium hydroxide," Dental Traumatology, vol. 27, no. 3, pp. 174-178, 2011.

[17] J. Tanalp, I. Dikbas, Ö. Malkondu, H. Ersev, T. Güngör, and G. Bayirli, "Comparison of the fracture resistance of simulated immature permanent teeth using various canal filling materials and fiber posts," Dental Traumatology, vol. 28, no. 6, pp. 457464, 2012.

[18] S. J. Schmoldt, T. C. Kirkpatrick, R. E. Rutledge, and J. M. Yaccino, "Reinforcement of simulated immature roots restored with composite resin, mineral trioxide aggregate, gutta-percha, or a fiber post after thermocycling," Journal of Endodontics, vol. 37, no. 10, pp. 1390-1393, 2011.

[19] A. M. Elnaghy and S. E. Elsaka, "Fracture resistance of simulated immature teeth filled with Biodentine and white mineral trioxide aggregate - an in vitro study," Dental Traumatology, vol. 32, no. 2, pp. 116-120, 2015.

[20] M. Parirokh and M. Torabinejad, "Calcium Silicate-Based Cements," in Mineral Trioxide Aggregate: Properties and Clinical Applications, M. Torabinejad, Ed., John Wiley \& Sons, Hoboken, NJ, USA, 1st edition, 2014.

[21] P. Z. Tawil, D. J. Duggan, and J. C. Galicia, "Mineral trioxide aggregate (MTA): its history, composition, and clinical applications," Compendium of Continuing Education in Dentistry, vol. 36, no. 4, pp. 247-264, 2015.

[22] Ö. I. A. Ulusoy, Y. Nayr, and S. Darendeliler-Yaman, "Effect of different root canal sealers on fracture strength of simulated immature roots," Oral Surgery, Oral Medicine, Oral Pathology, Oral Radiology and Endodontology, vol. 112, no. 4, pp. 544-547, 2011.

[23] Š. Hatibović-Kofman, L. Raimundo, L. Zheng, L. Chong, M. Friedman, and J. O. Andreasen, "Fracture resistance and histological findings of immature teeth treated with mineral trioxide aggregate," Dental Traumatology, vol. 24, no. 3, pp. 272-276, 2008.

[24] E. A. Bortoluzzi, E. M. Souza, J. M. S. N. Reis, R. M. Esberard, and M. Tanomaru-Filho, "Fracture strength of bovine incisors after intra-radicular treatment with MTA in an experimental immature tooth model," International Endodontic Journal, vol. 40, no. 9, pp. 684-691, 2007.
[25] M. Karapinar-Kazandag, B. Basrani, V. Tom-Kun Yamagishi, A. Azarpazhooh, and S. Friedman, "Fracture resistance of simulated immature tooth roots reinforced with MTA or restorative materials," Dental Traumatology, vol. 32, no. 2, pp. 146-152, 2016.

[26] H. Hemalatha, M. Sandeep, S. Kulkarni, and S. S. Yakub, "Evaluation of fracture resistance in simulated immature teeth using resilon and ribbond as root reinforcements-an in vitro study," Dental Traumatology, vol. 25, no. 4, pp. 433-438, 2009.

[27] B. Bolhari, E. Mojazi Amiri, H. Kermanshah, S. Ghabraei, and A. Jamei, "Fracture resistance of simulated immature teeth obturated with Gutta-Percha or Resilon and reinforced by composite or post," Journal of Dentistry, vol. 12, pp. 125-133, 2015.

[28] B. A. Damas, M. A. Wheater, J. S. Bringas, and M. M. Hoen, "Cytotoxicity comparison of mineral trioxide aggregates and EndoSequence bioceramic root repair materials," Journal of Endodontics, vol. 37, no. 3, pp. 372-375, 2011.

[29] V. Caronna, V. Himel, Q. Yu, J.-F. Zhang, and K. Sabey, "Comparison of the surface hardness among 3 materials used in an experimental apexification model under moist and dry environments," Journal of Endodontics, vol. 40, no. 7, pp. 986-989, 2014.

[30] I. D. Owadally and T. R. Pitt Ford, "Effect of addition of hydroxyapatite on the physical properties of IRM," International Endodontic Journal, vol. 27, no. 5, pp. 227-232, 1994.

[31] J. Camilleri, F. Sorrentino, and D. Damidot, "Characterization of un-hydrated and hydrated BioAggregate ${ }^{\mathrm{Tx}}$ and MTA Angelus s $^{\mathrm{nx} \text {," }}$ Clinical Oral Investigations, vol. 19, no. 3, pp. 689-698, 2015.

[32] J. Camilleri and M. G. Gandolfi, "Evaluation of the radiopacity of calcium silicate cements containing different radiopacifiers," International Endodontic Journal, vol. 43, no. 1, pp. 21-30, 2010.

[33] J. O. Andreasen, E. C. Munksgaard, and L. K. Bakland, "Comparison of fracture resistance in root canals of immature sheep teeth after filling with calcium hydroxide or MTA," Dental Traumatology, vol. 22, no. 3, pp. 154-156, 2006.

[34] L. M. Formosa, B. Mallia, and J. Camilleri, "A quantitative method for determining the antiwashout characteristics of cement-based dental materials including mineral trioxide aggregate," International Endodontic Journal, vol. 46, no. 2, pp. 179-186, 2013. 

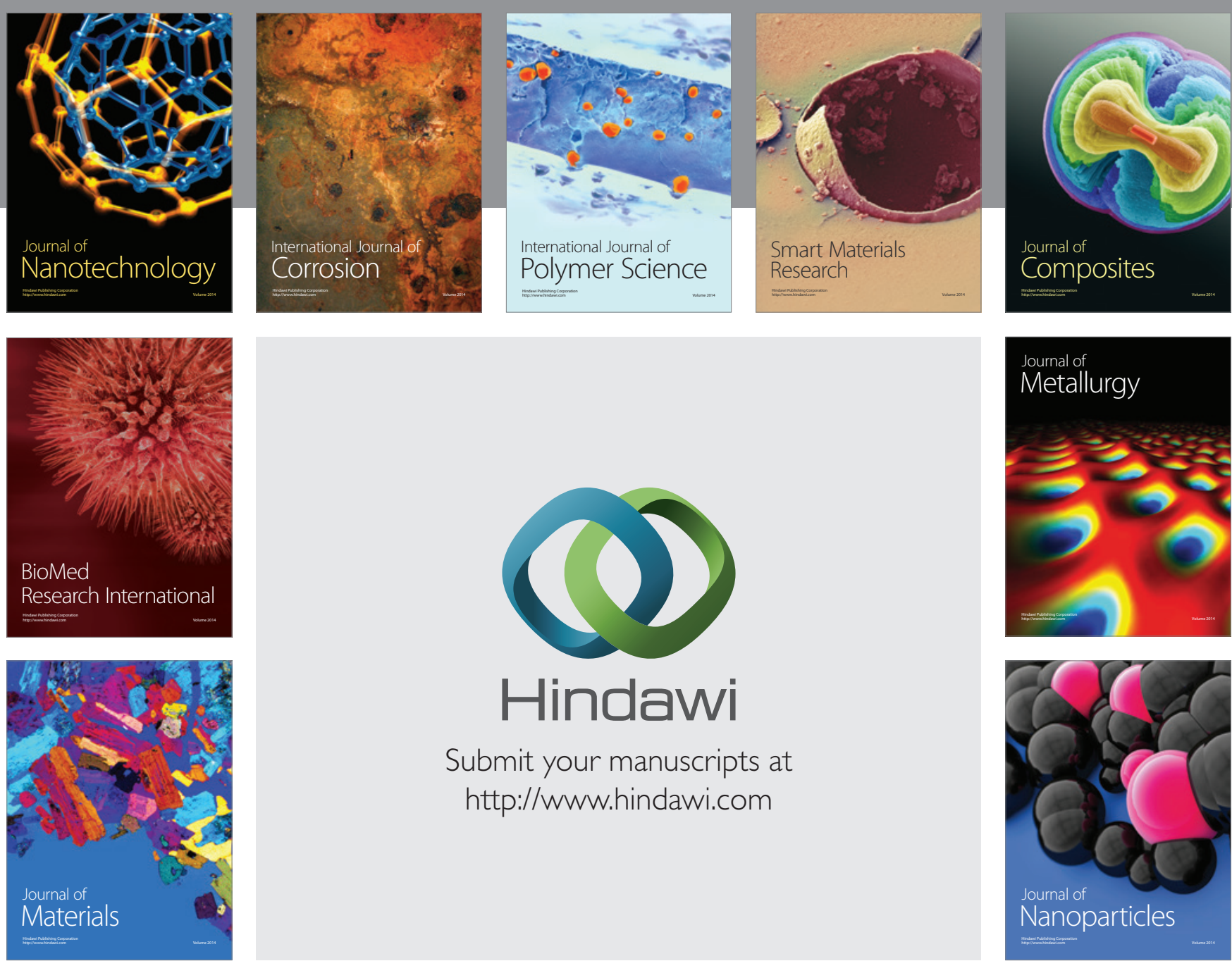

\section{Hindawi}

Submit your manuscripts at

http://www.hindawi.com

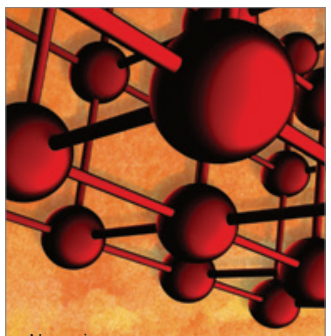

Materials Science and Engineering
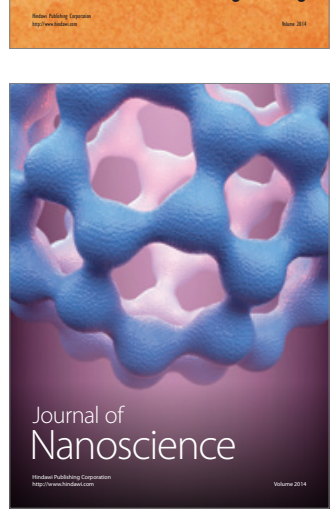
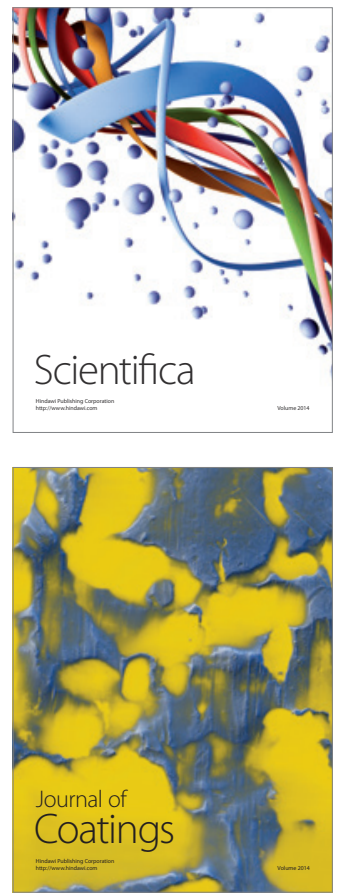
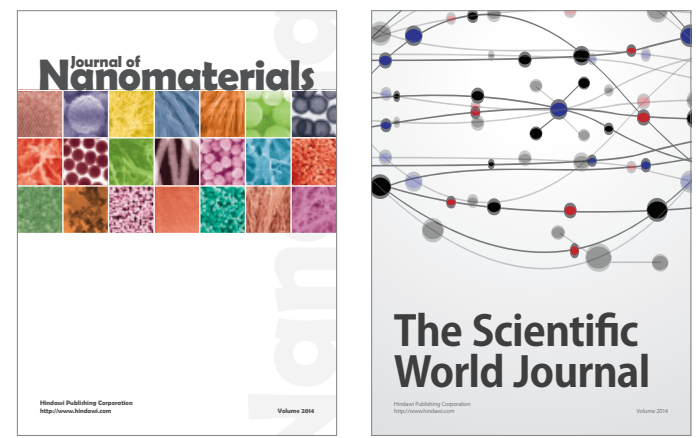

The Scientific World Journal
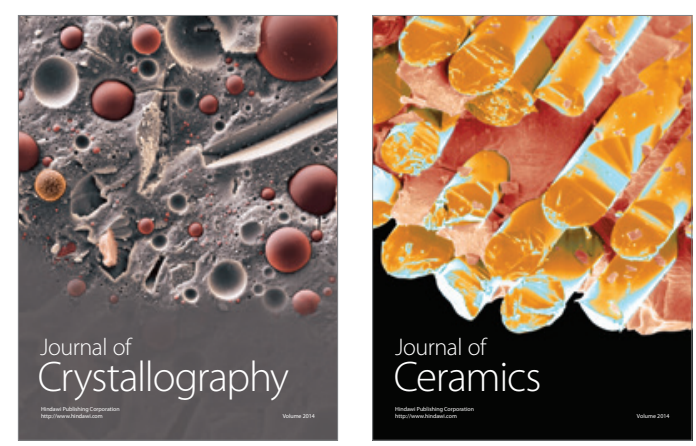
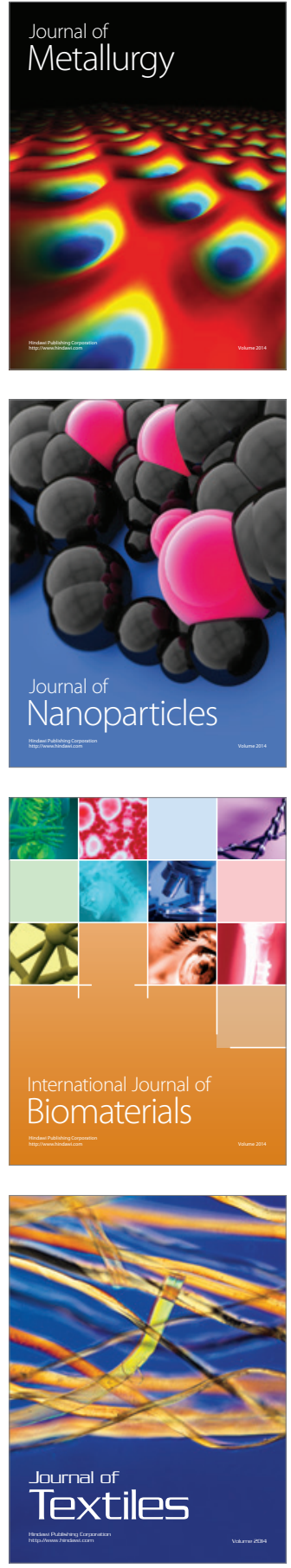